\title{
Eco-Technological Innovation of «Two Highs» Companies Under the Low-Carbon Economy Based on the Perspective of Game Theory
}

\author{
Zhenlian Tang, Razumovskiy Denis, Elena Razumovskaia*
}

\author{
Ural State Economic University, Russia, Yekaterinburg \\ "Corresponding author. Email: rasumovskaya.pochta@gmail.com
}

\begin{abstract}
Economic-oriented scientific and technological innovation must consider ecological principles to achieve sustainable economic development in the ecological sense. As the two most commonly used emission reduction systems to promote low-carbon development, carbon trading and carbon tax have their advantages and disadvantages and are both developmental. On this basis, from the perspective of game theory, this article analyzes the strategies of high-polluting and high-energy-consuming companies and the government and the strategies of high-polluting and high-energy companies and investors in the process of eco-technological innovation. Based on the game results, a new energy system with «UHV technology» as the core was designed, and the scientific and technological innovation and investment direction under this framework were pointed out.
\end{abstract}

Keywords: ecology, development of territories, low-carbon economy, technological innovation, game theory, new energy.

\section{INTRODUCTION}

Nowadays, researches on the environmental threats facing humanity is very relevant. They are all caused by human activities: emissions from car exhaust gases, emissions from companies with high levels of pollution, deforestation and high energy consumption. Energy neutrality is gaining more and more public attention around the world because of its warming carbon emissions [5]. On April 22, 2021, Earth Day, US President Biden convened a global «leadership climate summit». United Nations Secretary-General Guterres called on: «Countries should levy carbon taxes, stop fossil fuel subsidies, increase investment in renewable energy and ecological infrastructure, and stop new coal power plants» Among them, US President Biden said: «The United States is committed to reducing emissions by $50 \%-52 \%$ by $2030 »$; Russian President Putin said: «It will raise the priority of domestic ecological energy projects, and hope that the carbon emissions will be lower than the EU in the next 30 years.»; Chinese President Xi Jinping put forward: "China strives to achieve carbon peaks by 2030 and carbon neutrality by $2060 »$. Therefore, promoting low-carbon development has become a global consensus to solve ecological and environmental problems.

Countries have begun to improve their high-pollution emission systems and related standards gradually. Among them, carbon trading and carbon taxes are the two most commonly used emission reduction systems in countries worldwide. As a quantity-oriented policy tool, carbon trading is considered a typical application of a tradable pollution permit that conforms to the Coase theorem. The carbon tax is a price-oriented policy tool, similar to the Pigou tax in economics. At present, «Capand-Trade» has become the most effective market emission reduction mechanism for countries to control and reduce carbon emissions through the control of carbon caps, carbon emission reductions, and carbon trading (CET). At the same time, it is also an important measure to balance the low-carbon and economic nature of the system. Nevertheless, scholar Samaras et al. [8] pointed out that simply implementing the Cap-and-Trade regulation is insufficient to reduce carbon emissions effectively. To achieve this goal, it is also necessary to invest in carbon emission reduction technologies [3].

In the context of low-carbon development, almost all traditional and high-carbon energy sources may be 
replaced by new energy sources, and almost all highpolluting and high-energy-consuming companies may disappear. As far as the company is concerned. In order to get rid of the crisis of survival, high-pollution and high-energy-consuming companies (after this referred to as «two highs» companies) must strengthen investment in carbon emission reduction technologies, gain competitive market advantages by improving carbon purification capabilities, and reshape their companies through low-carbon transformation - core competitiveness. Therefore, the «two high» companies can achieve the goal of reducing emissions and improving market efficiency through ecological technology innovation, thereby solving problems such as climate change.

As far as the government is concerned. Tang Qingquan et al. [9] believe that government subsidies, as an essential economic incentive policy, can make up for market failures and play a significant role in promoting investment and economic growth, adjusting the industrial structure, and guiding economic trends. As far as investors are concerned. Wang Wei [10] analyzed the investment risk caused by the lack of accurate carbon information from investors' perspective based on the game of the company, the government, and investors and chose to withdraw the investment. Therefore, based on game theory, this paper analyzes the strategies of «two highs» companies and the government and the strategies of «two highs» companies and investors in technological innovation and designs the overall development framework of ecological technology innovation based on the game results

\section{METHODS}

Scientific research in the field of traditional ecology addresses the issues of modeling sustainable cities of the future [2] and overcoming poverty in a number of countries [7]. A special place in such studies is occupied by the transformation of urban landscapes [1]. The author's research focus is on the technological innovation game model of «two high» companies, mainly involving companies, investors and government. For companies, in choosing energy-saving and emission-reduction measures, due to the significant investment in high-tech innovation and slow results, the company will tend to choose other energy-saving and emission-reduction measures. For investors, if equity investors have shares in these high-carbon industries and companies, and these companies do not transform, then the valuation of these shares will likely become very small, or even zero, in the future, and investors will face investment risk. Company investors need to learn more about the company's relevant technical conditions, supervise the company's energy conservation and emission reduction, and take investment or non-investment per the information situation. For the government, it is necessary to supervise the energy conservation and emission reduction of the «two high» companies, provide financial subsidies to related companies through incentive policies, and then adopt a reward or non-reward for the supervision [4]. Through the analysis of the value orientation of the three different entities, it can be seen that the «two highs» companies mainly have two strategies in energy conservation and emission reduction measures: (innovation of ecological technology, not an innovation of ecological technology); investors have two strategies: (Investment, not investment); The government has two strategies: (reward, no reward).

\section{COMPANIES AND GOVERNMENTS}

In the context of low-carbon development, «two highs» companies will transform their companies through eco-technological innovation to obtain more investment [6]. They assumed that when ecotechnological innovation is not carried out, the company's normal income is E. When carrying out ecotechnological innovation, the cost invested by the company is $\mathrm{S}$, so the additional benefit obtained is $E_{0}$. When the government supervises the company's energy conservation and emission reduction, the supervision cost is $C$. The government has corresponding rewards for companies that carry out eco-technological innovations, and the reward amount is $G$. The company's other profits due to eco-technological innovation are $H$. Among them, $\alpha$ is the probability of the company's eco-technological technological innovation, $\beta$ is the probability of government supervision, and $\theta$ is the probability of discovering the company's eco-technological innovation during the process of government supervision. See Table 1 :

Table 1. Supervision game model between «two high» enterprises and the government

\begin{tabular}{|l|l|l|} 
Strategy & Supervision & not supervision \\
\hline $\begin{array}{l}\text { Green technology } \\
\text { innovation }\end{array}$ & $\begin{array}{l}\text { E+E0-S+ G }+ \text { +H } \theta, \\
-G \theta-C\end{array}$ & E+E0-S, 0 \\
\hline $\begin{array}{l}\text { Non-green } \\
\text { technological } \\
\text { innovation }\end{array}$ & E, -C & E, 0 \\
\hline
\end{tabular}

\subsection{In the Process of the Company's Eco- Technological Innovation, the Government's Expected Benefits Are:}

$$
\begin{gathered}
\mathrm{I}_{\text {supervision }}=-\mathrm{C}^{*}(1-\alpha)+\alpha *(-\mathrm{G} \theta-\mathrm{C}) \\
\mathrm{I}_{\text {no supervision }}=0
\end{gathered}
$$

By making the government's expected return during supervision and non-supervision equal, a Nash equilibrium solution can be obtained:

$$
\alpha=-\mathrm{C} / \mathrm{G} \theta
$$




\subsection{Under the Supervision of the Government, the Company's Expected Income Is:}

$$
\begin{aligned}
I_{\text {supervision }}= & \beta *(E+E 0-S+G \theta+H \theta)+(1-\beta) *(E+E 0-S) \\
& I_{\text {no supervision }}=\beta * E+E^{*}(1-\beta)
\end{aligned}
$$

If the company's expectation of eco-technological innovation is equal to the expected return of no ecotechnological innovation, a Nash equilibrium solution can be obtained:

$$
\beta=(\mathrm{S}-\mathrm{E} 0) /(\mathrm{G} \theta+\mathrm{H} \theta)
$$

\section{COMPANIES AND INVESTORS}

In order to avoid investment risks in advance in the context of low-carbon development, investors in the investment process will verify the relevant information of the «two high» companies and find that such companies have not carried out ecological technology innovation. They will reduce investment or even terminate investment. Suppose that when the company does not carry out ecological technology innovation, the company's normal return is $\mathrm{E}$, and the investor's normal return is $R$. When the company conducts ecotechnological innovation, the input cost is $S$, so the additional benefit obtained is E0. The cost invested by the investor in the process of verifying the company's situation is $Y$. When investors discover that the «two highs» company has not carried out eco-technological innovation, taking into account the investment risk, will withdraw the funds, the company's loss is $M$, and the investor's loss is $K$. Among them, $\alpha$ is the probability of the company's ecological technology innovation, $\beta$ is the probability of investors' investment, and $\delta$ is the probability of investors discovering that the company has not conducted ecological technology innovation during the supervision process. See Table 2 for details:

Table 2. Supervision game model between «two high» enterprises and the government

\begin{tabular}{l|l|l|} 
Strategy & Invest & not invest \\
\hline $\begin{array}{l}\text { Green technology } \\
\text { innovation }\end{array}$ & E+E0-S, R-Y & E+E0 -S, -Y \\
\hline $\begin{array}{l}\text { Non-green } \\
\text { technological } \\
\text { innovation }\end{array}$ & E-Mō, R-Y-Kō & E, -Y \\
\hline
\end{tabular}

\subsection{In the Process of the Company's Eco- Technological Innovation, the Investor's Expected Return Is:}

$$
\begin{gathered}
\mathrm{I}_{\text {Invest }}=(\mathrm{R}-\mathrm{Y}) * \alpha+(1-\alpha) *(\mathrm{R}-\mathrm{Y}-\mathrm{K} \delta) \\
\mathrm{I}_{\text {not invest }}=-\mathrm{Y} * \alpha+-\mathrm{Y} *(1-\alpha)
\end{gathered}
$$

By equalizing the expected return of investors when investing and not investing, a Nash equilibrium solution can be obtained:

$$
\alpha=1-\mathrm{R} / \mathrm{K} \delta
$$

\subsection{When the Investor Makes the Investment, the Company's Expected Return Is:}

$$
\begin{gathered}
I_{\text {supervision }}=\beta^{*}\left(E+E_{0}-S\right)+(1-\beta)^{*} \quad\left(E+E_{0}-S\right) \\
I_{\text {no supervision }}=\beta^{*} \quad(E-M \delta)+E^{*}(1-\beta)
\end{gathered}
$$

If the company's expectation of eco-technological innovation is equal to the expected return of not conducting eco-technological innovation, a Nash equilibrium solution can be obtained:

$$
\beta=\mathrm{E} /(1+\mathrm{M} \delta)
$$

\section{RESULTS}

\subsection{Analysis of the Results of the Game between the Company and the Government:}

In table 1, Equation (1), $\alpha=-\mathrm{C} / \mathrm{G} \theta$.

From the equilibrium solution of $\alpha$, it can be seen that the probability of «two highs» companies carrying out eco-technological innovation mainly depends on three variables, which are the cost $C$ of the government in supervision, the government's reward $G$ for companies that carry out eco-technological innovation, and the government's supervision process Discover the probability $\theta$ of the company's eco-technological innovation. As the reward $G$ increases, the probability $\alpha$ of the company's eco-technological innovation is higher. As the government recognizes the company that conducts eco-technological innovation, the company's probability for eco-technological innovation will also increase. To promote the company's eco-technological innovation, it is possible to reduce the cost of government supervision, increase rewards, and increase the probability of discovering that the company is carrying out ecotechnological innovation during government supervision.

\subsection{Analysis of the Results of the Game between the Company and Investor:}

In table 2, Equation (3), $\alpha=1-\mathrm{R} / \mathrm{K} \delta$.

From the equilibrium solution of $\alpha$, it can be seen that the probability of «two highs» companies carrying out ecological technology innovation mainly depends on three variables. When the company does not carry out ecological technology innovation, the investor's normal investment income $R$; because the company has not carried out ecological technology innovation, The investor loses $K$; the probability that the investor finds that the company has not carried out ecological technology innovation during the process of verifying the information $\theta . \alpha$ is negatively correlated with $R, K$, and $\delta$. The loss of investors can be reduced by increasing the company's probability of eco-technological innovation. 
At the same time, when investors find that the probability of the company's failure to carry out eco-technological innovation is reduced, it will prompt the company to carry out eco-technological innovation.

\section{CONCLUSION}

Based on the game results of the ecological technology innovation of the «two highs» companies, this paper designs the new energy and energy storage industry chain pyramid as shown in the figure below. Among them, the core part of the pyramid is the power grid represented by UHV transmission and DC power supply. It forms the transportation network of the energy system together with the previous transportation network, natural gas, and oil transportation pipeline network. At the bottom of the pyramid are the company and investors. The focus of technological innovation and investment on both sides will shift to the new energy industry chain and energy storage industry chain. This means that the energy storage problem under the new energy industry will also be a problem to be solved in the development of the new energy industry, that is, how to perform grid peak shaving and how to distribute and use the electricity generated by the new energy.

As shown in Figure 2, new energy sources such as photovoltaics and wind energy are responsible for power generation, UHV is responsible for energy distribution, and new energy vehicles are responsible for reserve consumption, forming a new system to move away from fossil energy and move towards new energy. At the same time, related industries and supporting facilities in the new energy industry chain and energy storage industry chain have huge investment potential.

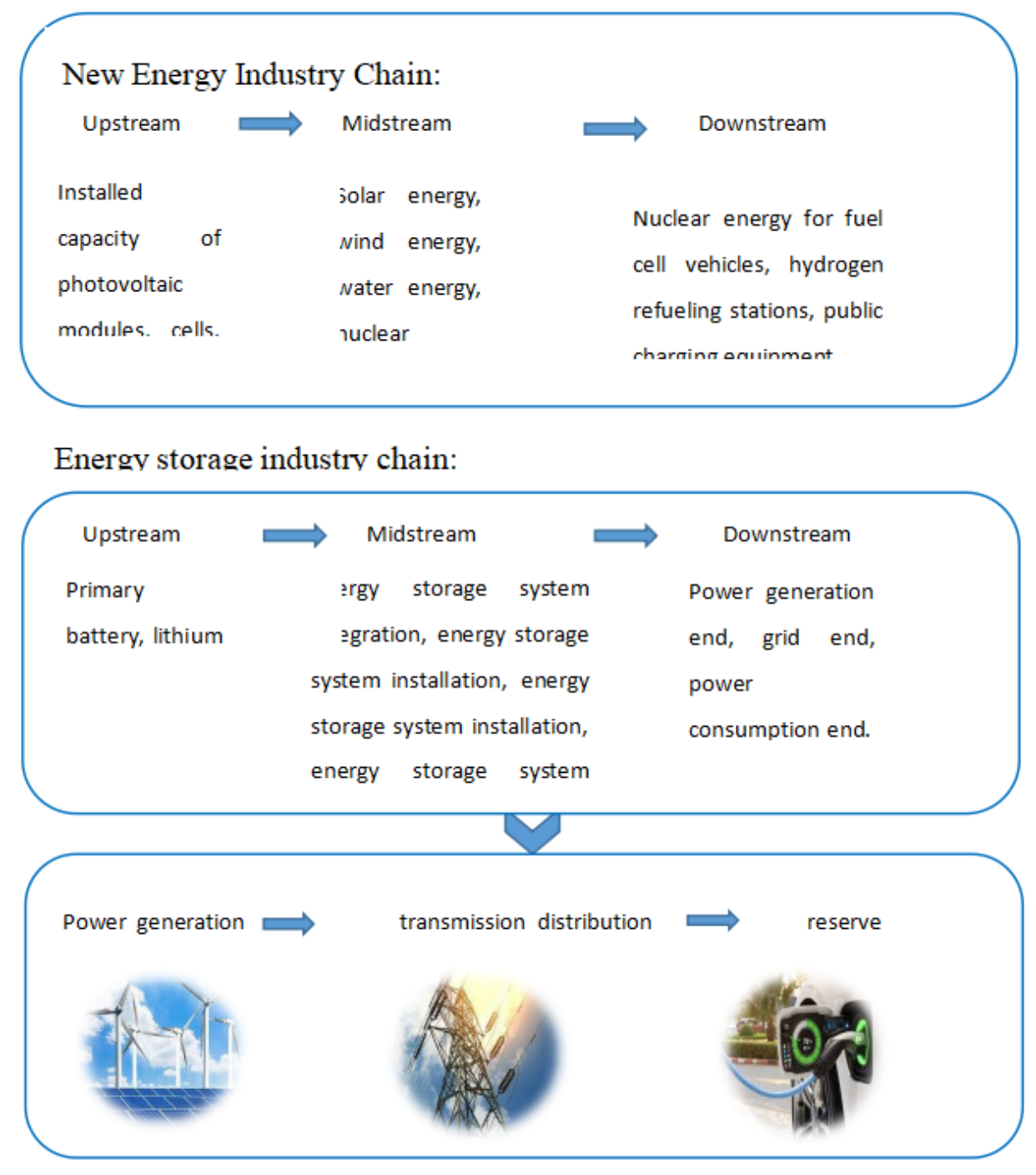

Figure 2. New energy and new system 


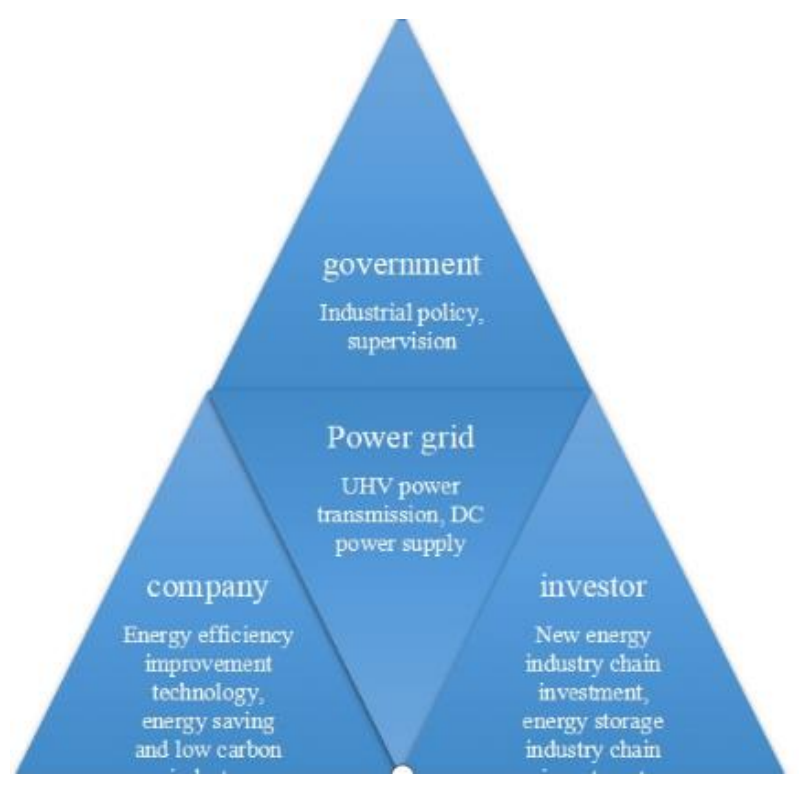

Figure 1. New energy and energy storage industry chain pyramid

Therefore, from the perspective of ecological and environmental protection, the new energy and system can reduce carbon dioxide emissions and promote the development of low-carbon industries; from the perspective of economic strategy, the new energy and new system can restrict the U.S. petrodollar hegemony and stabilize the world order; from the perspective of the technological revolution, the new energy system can force the upgrading of low-end industries and promote the reform and advancement of the technological level of all countries in the world, and enter a new era of resource utilization.

\section{REFERENCES}

[1] L. Albrechts, A. Barbanente, V. Monno, Practicing transformative planning: the territory-landscape plan as a catalyst for change. City Territ Archit (2020) pp. 7-1. DOI: https://doi.org/10.1186/s40410-019-0111-2.

[2] S.E. Bibri, J. Krogstie, A scholarly backcasting approach to a novel model for smart sustainable cities of the future: strategic problem orientation. City Territ Archit (2019) pp. 6-3. DOI: https://doi.org/10.1186/s40410-019-0102-3.

[3] D. F. Drake, S. Spinler, Sustainable operations manage-mentan enduring stream or a passing fancy. Manu-facturing and Service Operations Management, 15(4) (2013)pp. 13-49.

[4] Jia Xiangtong, The issue of ecological sustainable development from the perspective of scientific and technological innovation. People's Forum·Academic Frontiers,2020 (02) pp. 50-57.

[5] G. Lang, Urban energy futures: a comparative analysis. European Journal of Futures Research
(2018) pp. 6-19. DOI: https://doi.org/10.1186/s40309-018-0146-8.

[6] Lan Zirui, Sun Zhenqing, Cai Linlin, The evolutionary game of green innovation investment of upstream and downstream enterprises under the background of low carbon. Science and Technology Management Research,2019,39(16): pp. 257-263.

[7] A. Ragheb, R. El-Ashmawy, Strategic actions of urban development to define the intervention policies of slums. City Territ Archit (2021) pp. 8-10 DOI: https://doi.org/10.1186/s40410-021-00139W.

[8] C. Samaras, J. Apt, I. L. Azevedo, Cap and trade is notenough improving US climate policy. Garnegie Mellon Engineering Carnegie Institute of Technolog (2009).

[9] Tang Qingquan, Luo Danglun, Empirical Research on the Motivation and Effects of Government Subsidies: Empirical Evidence from Chinese Listed Companies. Financial Research, 6 (2007).

[10] Wang Wei, Research on the Carbon Information Disclosure System of Listed Companies Based on the Game Theory Perspective. Accounting Communications,2021(14) pp. 105-140. 